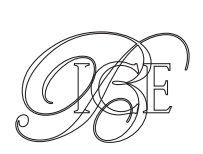

\title{
LA ECONOMÍA INTERNACIONAL DE CASTILLA-LA MANCHA 2020-2021
}

Este artículo pasa revista a todos los aspectos relevantes de la actividad exterior de las empresas castellanomanchegas en 2020, así como una previsión para 2021, a partir de los datos publicados del primer trimestre del año. Incluye un estudio de los flujos comerciales y el perfil de la empresa exportadora en las cinco provincias de la región y su distribución geográfica y sectorial, al margen de operaciones puntuales o extraordinarias que se pudieran producir. En un marco económico fuertemente marcado por la COVID-19, la internacionalización - aún con sus limitaciones - se ha constituido como una sólida estrategia para que las empresas consoliden su recuperación, diversifiquen riesgos y expandan sus tipos de mercado objetivo, aprovechando las oportunidades que la economía mundial nos ofrece. Conocer los riesgos a los que nos enfrentamos y los instrumentos a nuestra disposición son los ingredientes clave para el éxito y es, a esta tarea, a la que se orienta el informe que acabamos de elaborar.

Palabras clave: comercio exterior, empresas exportadoras, flujos comerciales, inversión extranjera. Clasificación JEL: E60, F14, R10.

\section{Introducción}

El presente informe trata de abordar, desde diferentes perspectivas económicas y comerciales, la coyuntura del sector exterior de

* Secretaría de Estado de Comercio. Este artículo ha sido elaborado por María Moya Sanmiguel, Graduado en Derecho y ADE, Máster en Negocios Internacionales (UCLM); Javier Cortés Huertas, Graduado en Derecho, Máster en Negocios Internacionales (UCLM); José Herrera Ares, Responsable de Informática, D.T. Toledo; Javier López Moya, Jefe de Sector de ICEX y Economista; Inmaculada Zayas Ludeña, Jefa de Servicio de Comercio e Inspectora del SOIVRE; y por Pedro A. Morejón Ramos, Director Territorial de Comercio, Técnico Comercial y Economista del Estado.

Versión de septiembre de 2021.

DOI: https://doi.org/10.32796/bice.2021.3139.7287

Nota: se permite la reproducción para fines docentes o sin ánimo de lucro, siempre que se cite la fuente.
Castilla-La Mancha, en lo sucesivo CLM, a lo largo del ejercicio 2020 con una proyección para 2021, destacando los aspectos positivos, pero también los puntos débiles, en el proceso de internacionalización de esta comunidad autónoma, cuya apertura al exterior es relativamente reciente, pero, por ello, de un mayor interés si cabe.

En definitiva, el objetivo del presente documento se resume en dar una visión lo más completa posible de la economía castellanomanchega en su vertiente internacional. La ordenación que le hemos dado persigue facilitar su uso e interpretación a los profesionales de la economía, a las instituciones y entidades $\triangleright$ 
socioeconómicas y, por supuesto, a las empresas que desarrollan o piensan desarrollar su actividad económica en esta región, con el objetivo de colaborar y ser de utilidad en el desenvolvimiento de una política ortodoxa de internacionalización en función de las ventajas comparativas que tiene Castilla-La Mancha, lo que redundará en el crecimiento de la economía regional y, en consecuencia, en la mejora del nivel de vida de sus ciudadanos.

\section{Estructura económica de Castilla-La Mancha}

A la espera de publicación por parte del INE de los datos oficiales del PIB para 2020 en España y Castilla-La Mancha, las estimaciones que se manejan situarían el dato a nivel nacional en una caída de en torno al $11 \%$ (según la OCDE), mientras que en Castilla-La Mancha la crisis de la COVID-19 tendría un menor impacto y situaría el descenso del PIB entre el -6 y el $-7 \%$ (según FUNCAS y el Boletín Económico de Castilla-La Mancha).

Por lo que respecta a los indicadores de población y empleo de nuestra región en 2020, el volumen de población activa disminuye, por la salida del mundo laboral de 14.000 trabajadores, lo que situó la tasa de actividad en el 57,11 \%. La tasa de ocupación (48,4\%) cayó ligeramente, perdiendo 11.900 puestos de trabajo y rompiendo la tendencia positiva de años anteriores. Todo esto se traduce en un ligero aumento de la tasa de paro, hasta alcanzar el $17,68 \%$ en 2020 , un punto y cuatro décimas superior a 2019, pero aún con una reducción si la comparamos con la tasa del 19,74\% en 2017 y del 22,14\% de 2016 . A pesar de ello, las cifras registradas nos colocan más de dos puntos porcentuales por encima de la tasa de paro nacional (15,53\%).

\section{Evolución histórica del comercio exterior en Castilla-La Mancha}

El comercio exterior en Castilla-La Mancha muestra una tendencia creciente en su ritmo exportador que puede clasificarse en varias etapas diferenciadas.

Un periodo de fuerte expansión (1992-1998) en el que el volumen de exportación casi se cuadruplicó, desde los 475 millones de euros (en adelante $\mathrm{M} €$ ) hasta $1.734 \mathrm{M} €$, frenado por una caída del $8 \%$ en 1999. A partir del año 2000 y hasta 2008 , se inicia una nueva etapa alcista, con tasas de crecimiento de las exportaciones en torno al 7\%, destacando especialmente el año 2004, en el que el crecimiento alcanzó el $13 \%$, debido a la ampliación de la UE a veinticinco socios y a la recuperación de los sectores de bienes de equipo, semimanufacturas y agroalimentario.

En 2009 la crisis de las hipotecas subprime, originada en Estados Unidos el año anterior, contagió al sistema financiero internacional, provocando una profunda crisis de liquidez a nivel global que tuvo como consecuencia el desplome del comercio mundial. Las exportaciones de Castilla-La Mancha descendieron un $9 \%$ ese año. La crisis financiera en España se vio agravada por una excesiva dependencia de la economía en el sector de la construcción. Vista la fuerte debilidad de la demanda nacional, las empresas trataron de dirigir sus esfuerzos comerciales al exterior. Las exportaciones se convirtieron desde entonces en la «tabla de salvación» de numerosas empresas, muchas de las cuales han visto minimizados sus riesgos comerciales al tener diversificada su cartera de clientes en diversos países. Así, entre 2010 y 2017 las exportaciones de la región crecieron a una tasa de dos dígitos, mientras que en 2018 y 2019 ese crecimiento se ha $\triangleright$ 
ralentizado, presentando una tasa de variación de en torno al 3\%. Como consecuencia, CastiIla-La Mancha ha pasado de representar el $1,5 \%$ de toda la exportación española en 1997 al 2,8\% en 2020. Además, la contribución de las exportaciones de Castilla-La Mancha al PIB regional se ha duplicado desde 2010, pasando del $8 \%$ al $17 \%$.

Por otro lado, la evolución de las importaciones regionales ha seguido una tendencia más irregular en los últimos años, lejos de la que se inició en 1986 tras la apertura de la economía española a la Unión Europea y que se vio acentuada en los años de mayor crecimiento económico.

No obstante, también podemos distinguir varias etapas claramente diferenciadas:

- Periodo 1992-1996, en el que experimentaron crecimientos anuales entre el $7 \%$ y el $9 \%$.

- Periodo 1997-2004, en el que se pasó de $1.835 \mathrm{M} €$ a $4.803 \mathrm{M} €$, con tasas de crecimiento anuales entre el $13 \%$ y el $23 \%$, salvo en el año 2002, que fue de casi el $4 \%$. En el año 2004 se igualan el crecimiento importador y el exportador, ambos con el $13,4 \%$, aunque con un volumen muy distinto.

- En 2005 se registra, por primera vez desde que se tienen datos, una bajada en las importaciones de casi el $9 \%$. Pero en 2006 y 2007 se invierte esta situación, alcanzándose cifras récord de 5.927 M€ y un incremento del 26,6\%, y de 8.147 M€ y una subida del $37,5 \%$, respectivamente.

- En 2008, se vuelven a frenar las importaciones con un descenso del $18,2 \%$, influido sobre todo por el parón de la automoción, sector dominante de nuestras compras, y que se acentuó en 2009 con una caída del $28,8 \%$, para recuperarse ligeramente en 2010 con un incremento del $9,5 \%$.

- En 2011 y 2012, como consecuencia de la crisis financiera internacional y el estallido de la burbuja inmobiliaria en nuestro país, nuestra capacidad de compra se reduce y, por tanto, las importaciones siguen una tendencia negativa, con sendos descensos del $1,5 \%$ y $4,4 \%$ respectivamente, y un volumen cercano al alcanzado en 2009, en que se produjo la mayor caída de nuestras compras al exterior.

- Sin embargo, en 2013 se recupera el aumento en las importaciones, con una tasa de crecimiento del $16,7 \%$, que se consolida en 2014 (4,5\%), 2015 (11\%), 2016 (12,6\%), 2017 (13,8\%), 2018 $(8,5 \%)$ y $2019(0,7 \%)$.

- En 2020 las importaciones han caído un $0,2 \%$ respecto al año anterior, caída que puede deberse a la parada en los procesos productivos por la pandemia.

En definitiva, si analizamos la evolución de las importaciones desde 1997, año en el que esta Dirección Territorial comenzó sus estudios sobre los flujos comerciales de la región, observamos que estas han pasado de $1.835 \mathrm{M} €$ a 9.285,7 M€ en 2020.

Comparando exportaciones e importaciones, observamos una mejora transitoria de nuestro déficit comercial en los años posteriores a la crisis —que alcanzó su mínimo en 2012 con $560 \mathrm{M€}$ - como consecuencia de fuertes crecimientos en las exportaciones y leves descensos en las importaciones. En los últimos años estamos viendo cómo el ritmo de crecimiento de las importaciones no solo se está $\square$ 
por la caída de las exportaciones. De modo que, en este periodo de estudio, el valor de la tasa de cobertura es de $77,4 \%$, (un $4,5 \%$ inferior a la del año anterior) y está por debajo de la media nacional, 95,1\% (5,6\% superior al año anterior), debido a la caída del $10 \%$ de las exportaciones y del $14,7 \%$ de las importaciones nacionales.

\section{Análisis sectorial del comercio exterior de Castilla-La Mancha en 2020}

\subsection{Análisis sectorial de la exportación}

A pesar del elevado peso del sector agrícola, desde el punto de vista exportador, Castilla-La Mancha es una región eminentemente industrial. En 2020, aproximadamente uno de cada dos euros facturados al exterior procedía del sector industrial. Las ventas de productos agroalimentarios perdieron peso y representaron el
$37,7 \%$ del total, mientras que los bienes de consumo representaron el 13,6\%.

En 2020 el primer capítulo exportador en la región fueron las bebidas (900,8 M€), fundamentalmente de la partida de vino (645 M€). Las ventas de vino solo bajaron un $1,4 \%$ en este periodo, a pesar de la parada del canal HORECA por el cierre de la restauración y la hostelería durante la pandemia. Como viene siendo habitual, el vino castellanomanchego presenta un precio bajo en los mercados internacionales debido al formato de venta a granel, que reduce el margen disponible respecto al embotellado y el valor añadido de un buen proceso enológico, a la vez que introduce volatilidad en el precio.

El segundo capítulo exportador fue el de aparatos y material eléctrico (706 M€), cuyas ventas aumentaron un 2,6\%. En este capítulo son especialmente relevantes los acumuladores eléctricos (178 M€) y los teléfonos móviles (148 M€). También son destacables las $\triangleright$

CUADRO 2

PRINCIPALES CAPÍTULOS DE EXPORTACIÓN DE CASTILLA-LA MANCHA*

(Millones de euros)

\begin{tabular}{|c|c|c|c|c|c|c|c|}
\hline \multirow{2}{*}{$\begin{array}{l}\text { Capítulos exportados } \\
\text { (Arancel Taric) }\end{array}$} & \multicolumn{3}{|c|}{ España } & \multicolumn{4}{|c|}{ Castilla-La Mancha } \\
\hline & 2020 & $\begin{array}{c}\% \\
20 / 19\end{array}$ & $\begin{array}{c}\% \text { s/total } \\
\text { exp. España }\end{array}$ & 2020 & $\begin{array}{c}\% \\
20 / 19\end{array}$ & $\begin{array}{l}\% \text { s/total } \\
\exp \text { CLM }\end{array}$ & $\begin{array}{c}\% \text { s/total sector } \\
\text { España }\end{array}$ \\
\hline 22 Bebidas todo tipo (exc. zumos) & $4.347,5$ & $-2,7$ & 1,7 & 900,8 & $-5,8$ & 12,5 & 20,7 \\
\hline 85 Aparatos y material eléctricos & $14.929,7$ & $-7,3$ & 5,7 & 706,0 & 2,6 & 9,8 & 4,7 \\
\hline 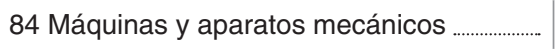 & $18.991,4$ & $-12,0$ & 7,3 & 625,5 & 1,4 & 8,7 & 3,3 \\
\hline 02 Carne y despojos comestibles & $8.436,5$ & 18,0 & 3,2 & 450,3 & 15,3 & 6,3 & 5,3 \\
\hline 39 Mat. plásticas; sus manufacturas ................ & $10.084,4$ & $-7,6$ & 3,9 & 332,4 & $-21,4$ & 4,6 & 3,3 \\
\hline 04 Leche, productos lácteos; huevos .............. & $1.562,2$ & 5,7 & 0,6 & 293,2 & 12,1 & 4,1 & 18,8 \\
\hline 87 Vehículos automóviles; tractor ........................ & $42.282,6$ & $-12,4$ & 16,2 & 274,8 & 14,2 & 3,8 & 0,6 \\
\hline 76 Aluminio y sus manufacturas & $3.133,1$ & $-11,2$ & 1,2 & 248,9 & $-3,4$ & 3,5 & 7,9 \\
\hline 61 Prendas de vestir, de punto & $4.389,3$ & $-14,0$ & 1,7 & 226,4 & $-22,2$ & 3,1 & 5,2 \\
\hline 62 Prendas de vestir, no de punto & $5.763,3$ & $-24,7$ & 2,2 & 192,8 & $-24,1$ & 2,7 & 3,3 \\
\hline Subtotal (10 sectores) & $113.920,0$ & $-9,8$ & 43,6 & $4.251,1$ & $-2,9$ & 59,1 & 3,7 \\
\hline Resto sectores & $147.255,5$ & $-10,1$ & 56,4 & $2.937,0$ & $-6,7$ & 40,9 & 2,0 \\
\hline Total exportación & $261.175,5$ & $-10,0$ & 100,0 & $7.188,1$ & $-4,5$ & 100,0 & 2,8 \\
\hline
\end{tabular}


ventas al exterior de relés (107 M€) y transformadores eléctricos (74 M€).

El tercer capítulo en importancia en 2020 fueron las máquinas y aparatos mecánicos (625 M€), cuyas ventas registraron un ligero aumento del 1,4\%. En este capítulo destacan las partes de motores (185 M€) y los ordenadores portátiles (124 M€).

Carne y despojos comestibles ocupan el cuarto puesto. Las exportaciones alcanzaron los $450 \mathrm{M} €$ y subieron un $15,3 \%$, por el buen comportamiento de la carne de porcino fresca y congelada.

Las materias plásticas (332 M€) se sitúan en quinto lugar a pesar de registrar un descenso en las exportaciones del $21,4 \%$, debido a la caída de las ventas de polímeros y poliacetales a países de nuestro entorno (Portugal, Francia, Alemania, Italia) y Turquía.

En lo que respecta a los sectores tradicionales de Castilla-La Mancha, las exportaciones de aceite de oliva han caído en 2020 (163 M€). Las ventas a Italia, nuestro principal cliente (con un $60 \%$ sobre el total), han caído un $23 \%$; Japón se mantiene como segundo destino con una ligera caída, seguido de Francia, Portugal y EE. UU. (mercado en el que siguen disminuyendo los envíos un 6,3\% en 2020), seguido de cerca por China, que en 2020 aumentaron en un $80 \%$.

El queso merece una mención especial. Castilla-La Mancha es la primera comunidad autónoma exportadora de queso en España: el queso manchego es nuestro queso más internacional y se ha convertido en uno de los pocos productos cuyas ventas al exterior no solo no han descendido -ni siquiera en los peores años de la crisis de 2008-, sino que, además, ha logrado casi triplicar su cifra de exportación en los últimos diez años, hasta los $149 \mathrm{M€}$. En 2020 , las exportaciones aumentaron un $9,5 \%$ respecto a 2019, a pesar del efecto de las medidas de retorsión aplicadas por Estados Unidos contra la UE por el caso Airbus.

\subsection{Análisis sectorial de la importación}

En el año 2020, las importaciones se mantuvieron estables respecto a 2019. Por sectores, el de las manufacturas supone el 50,5\% del total de las importaciones de Castilla-La Mancha, seguido de lejos por las semimanufacturas con un $31 \%$ y el sector primario con un $18,2 \%$. Los subsectores que mayores compras al exterior generan en la región son los bienes de equipo, que supusieron el $37,8 \%$ y que han presentado un crecimiento del $4,0 \%$; la industria química, que contribuye con un $23,3 \%$ al total de las importaciones con un aumento del 3,5\% respecto a 2019; y, en tercer lugar, los productos agroalimentarios, que supusieron el $16,6 \%$ y que en 2020 han caído un $2,6 \%$.

En cuanto al peso relativo de las importaciones de la región sobre el total nacional hay que destacar que los porcentajes son muy pequeños, contribuyendo por importancia el sector primario con un $3,7 \%$, el sector de las semimanufacturas con un $3,9 \%$ y el sector de las manufacturas con un $3,6 \%$.

\section{Análisis geográfico del comercio exterior en Castilla-La Mancha en 2020}

Desde el punto de vista del análisis geográfico del comercio exterior en Castilla-La Mancha podemos afirmar que existe una concentración geográfica de las exportaciones e importaciones de Castilla-La Mancha en la $D$ 
CUADRO 3

PRINCIPALES PAÍSES EN EL COMERCIO EXTERIOR DE CASTILLA-LA MANCHA

(Millones de euros)

\begin{tabular}{|c|c|c|c|c|c|c|c|c|}
\hline \multirow[b]{2}{*}{ Países } & \multicolumn{3}{|c|}{ Exportación } & \multicolumn{3}{|c|}{ Importación } & \multicolumn{2}{|c|}{ Saldo } \\
\hline & 2020 & $\begin{array}{c}\% \\
20 / 19\end{array}$ & $\begin{array}{c}\% \mathrm{~s} / \\
\text { total } 20\end{array}$ & 2020 & $\begin{array}{c}\% \\
20 / 19\end{array}$ & $\begin{array}{c}\% \mathrm{~s} / \\
\text { total } 20\end{array}$ & 2020 & $\begin{array}{c}\% \\
20 / 19\end{array}$ \\
\hline Portugal ... & $1.449,5$ & $-10,8$ & 20,2 & 490,1 & 2,9 & 5,3 & 959,4 & $-16,5$ \\
\hline Francia & $1.084,6$ & 3,5 & 15,1 & $1.200,1$ & $-7,3$ & 12,9 & $-115,6$ & $-53,3$ \\
\hline Alemania .. & 680,9 & $-7,0$ & 9,5 & $1.675,4$ & 20,5 & 18,0 & $-994,6$ & 51,1 \\
\hline Italia ......... & 551,7 & $-11,9$ & 7,7 & 640,3 & 0,7 & 6,9 & $-88,6$ & 809,1 \\
\hline Estados Unidos & 319,7 & 7,0 & 4,4 & 198,8 & $-8,2$ & 2,1 & 120,9 & 47,2 \\
\hline Reino Unido.. & 314,1 & $-1,1$ & 4,4 & 253,1 & $-23,6$ & 2,7 & 60,9 & $-544,0$ \\
\hline China ... & 248,8 & 24,4 & 3,5 & 913,8 & 0,6 & 9,8 & $-664,9$ & $-6,1$ \\
\hline Bélgica .... & 210,6 & 80,3 & 2,9 & 347,2 & 6,5 & 3,7 & $-136,6$ & $-34,7$ \\
\hline Países Bajos ... & 181,7 & $-2,6$ & 2,5 & 771,4 & $-4,5$ & 8,3 & $-589,7$ & $-5,1$ \\
\hline Polonia ........ & 173,2 & $-5,1$ & 2,4 & 270,2 & $-1,4$ & 2,9 & $-96,9$ & 5,8 \\
\hline Subtotal (10 países) & $5.214,7$ & $-2,2$ & 72,5 & $6.760,4$ & 1,5 & 72,8 & $-1.545,7$ & 16,4 \\
\hline Turquía .. & 154,5 & $-17,9$ & 2,1 & 218,2 & 17,2 & 2,4 & $-63,7$ & $-3.103,2$ \\
\hline 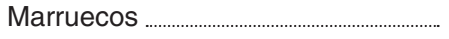 & 130,8 & $-2,5$ & 1,8 & 32,6 & $-1,8$ & 0,4 & 98,1 & $-2,7$ \\
\hline Japón ....... & 87,8 & 1,6 & 1,2 & 39,9 & $-23,7$ & 0,4 & 47,9 & 40,3 \\
\hline Suecia ........ & 85,5 & 118,9 & 1,2 & 119,6 & 37,0 & 1,3 & $-34,1$ & $-29,3$ \\
\hline México & 79,9 & $-22,0$ & 1,1 & 20,4 & $-49,0$ & 0,2 & 59,5 & $-4,7$ \\
\hline Rusia ........... & 70,8 & $-26,3$ & 1,0 & 7,6 & $-37,8$ & 0,1 & 63,1 & $-24,6$ \\
\hline Dinamarca & 60,2 & 5,9 & 0,8 & 62,3 & $-7,5$ & 0,7 & $-2,1$ & $-80,0$ \\
\hline República Checa & 54,0 & 24,7 & 0,8 & 113,7 & $-18,7$ & 1,2 & $-59,7$ & $-38,2$ \\
\hline 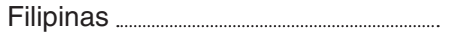 & 49,1 & $-24,6$ & 0,7 & 12,3 & 167,5 & 0,1 & 36,8 & $-39,3$ \\
\hline Arabia Saudí & 44,8 & 14,0 & 0,6 & 4,9 & $-9,6$ & 0,1 & 39,9 & 17,8 \\
\hline Subtotal (20 países) & $6.032,1$ & $-2,5$ & 83,9 & $7.392,0$ & 1,4 & 79,6 & $-1.359,8$ & 23,0 \\
\hline Rumanía ...... & 43,7 & $-13,8$ & 0,6 & 34,4 & 15,2 & 0,4 & 9,3 & $-55,4$ \\
\hline Finlandia & 41,8 & 11,2 & 0,6 & 11,4 & $-33,1$ & 0,1 & 30,5 & 47,7 \\
\hline Emiratos Árabes Unidos & 38,6 & 0,0 & 0,5 & 0,1 & $-80,6$ & 0,0 & 38,5 & 0,8 \\
\hline Irlanda ... & 37,4 & 22,1 & 0,5 & 561,1 & $-9,6$ & 6,0 & $-523,7$ & $-11,3$ \\
\hline Argelia . & 37,3 & $-19,6$ & 0,5 & 0,1 & $-45,7$ & 0,0 & 37,2 & $-19,5$ \\
\hline Israel ... & 37,2 & $-1,4$ & 0,5 & 11,2 & 27,0 & 0,1 & 26,1 & $-10,0$ \\
\hline Líbano ......... & 37,2 & 144,5 & 0,5 & 1,1 & $-65,4$ & 0,0 & 36,1 & 197,1 \\
\hline Canadá ... & 35,5 & $-5,6$ & 0,5 & 17,0 & $-8,1$ & 0,2 & 18,6 & $-3,2$ \\
\hline Corea del Sur (Rep. de Corea) ............ & 35,3 & $-25,5$ & 0,5 & 57,4 & 331,0 & 0,6 & $-22,0$ & $-164,5$ \\
\hline Grecia ... & 34,3 & 5,8 & 0,5 & 28,4 & $-0,7$ & 0,3 & 6,0 & 53,0 \\
\hline Subtotal (30 países) .. & $6.410,5$ & $-2,3$ & 89,2 & $8.113,8$ & 1,0 & 87,4 & $-1.703,3$ & 15,7 \\
\hline Total CLM & $7.188,1$ & $-4,5$ & 100,0 & $9.285,7$ & 0,0 & 100,0 & $-2.097,5$ & 19,1 \\
\hline
\end{tabular}

Unión Europea. Ello hace que no pueda hablarse de un comercio "genuinamente» internacional, en la medida en que las transacciones son ajenas a medidas de política comercial, se desarrollan en un contexto de libre circulación de mercancías o, incluso, entre países con una misma moneda (UEM).

No obstante, venimos observando una progresiva reducción de esa concentración en los mercados comunitarios. Así, en $2008 \triangleright$ 
Europa representaba más del $80 \%$ de la exportación de Castilla-La Mancha, mientras que en 2020 ha pasado a ser el $76 \%$. Por su parte, las importaciones procedentes de Europa han pasado de representar el $83,4 \%$ del total al $77,5 \%$. Esa menor concentración en la exportación se ha reflejado en un aumento del peso específico de América, que ha crecido del $6,1 \%(2008)$ al 8,2\% (2020), y Asia, que ha pasado del $4,8 \%$ (2008) al $10,5 \%$ y que ya en 2017 superó al continente americano como destino de nuestra exportación. Portugal (1.449,5 M€), Francia (1.084,6 M€) y Alemania (680,9 M€) vienen siendo desde hace años los principales destinos de la exportación de Castilla-La Mancha.

En 2020 las expediciones a Portugal cayeron un $10,8 \%$ por las caídas de gran parte de las partidas exportadas, debidas en gran medida a la parada del comercio intraindustrial que se produjo por la pandemia.

Las expediciones de la región a Francia están muy concentradas: las 20 partidas más exportadas supusieron el $87 \%$ de los envíos. Este año, a diferencia del anterior, los envíos han aumentado en un 3,5\%. La caída del vino y del aluminio y de materias plásticas ha sido prácticamente compensada con las fuertes subidas del resto de partidas, que han presentado incrementos dentro de las diez primeras. Destaca la subida de los aparatos y el material eléctrico, con un nuevo máximo en la serie histórica de 179 M€ y representando el $16 \%$ del valor del conjunto de bienes que se exportan al país vecino.

Las exportaciones a Alemania en 2020 disminuyeron en un $7 \%$ respecto al año anterior. La primera partida en importancia en las ventas a Alemania sigue siendo la de vino (157 M€), que aumentó en un 9,1\%, seguida de carnes y despojos (50 M€), que este año avanza posiciones y se sitúa en segundo puesto del ranking, y de aparatos y material eléctrico (43 M€). La caída de las exportaciones se debe en gran parte a la fuerte caída de las ventas de aeronaves y vehículos espaciales (-39\%) y de materias plásticas y sus manufacturas (-29\%).

Italia (552 M€) ha reducido las compras a la región. Aceite de oliva virgen, vino a granel y vehículos automóviles han sido las primeras partidas más vendidas.

Bélgica (211 M€), debido a la salida de la UE por parte de Reino Unido, avanza posiciones y se sitúa en el quinto puesto del ranking. Los principales productos enviados a Bélgica desde la región son: jeringuillas y catéteres, aparatos de alumbrado, sal, vinos embotellados y barras y perfiles de aluminio.

Estos cinco países completarían las cinco primeras posiciones entre los clientes de Castilla-La Mancha, y supusieron el $82 \%$ de los envíos a la Unión Europea.

Fuera de la UE, el primer destino de las exportaciones castellanomanchegas en 2020 fue EE. UU., que se sitúa como segundo país fuera de la UE (319 M€), con un incremento del 7\% respecto a 2019. Las cinco primeras partidas enviadas son: maquinaria y aparatos mecánicos, leche y productos lácteos, aparatos y máquinas eléctricas, calzado y bebidas (en especial los vinos).

En 2020 China fue nuestro tercer cliente no comunitario, con unas ventas que alcanzaron los $248 \mathrm{M} €$, lo que supuso un aumento del $24,4 \%$ respecto al año anterior. La exportación castellanomanchega al gigante asiático se concentra en productos agroalimentarios como carne y despojos (carne congelada de porcino), leche y productos lácteos, bebidas (vino), otros productos de origen animal (huesos desgelatinizados) y vidrio y sus manufacturas. 
Turquía, con un volumen de exportación de $154 \mathrm{M} €$, es desde 2014 nuestro cuarto cliente no comunitario. En 2020 las ventas a Turquía han caído un $17,9 \%$, debido en gran medida al aumento de las materias plásticas, de las prendas de vestir y de los productos farmacéuticos.

Las exportaciones a Marruecos, otro de los socios preferentes para España y que ocupa el 12. ${ }^{\circ}$ puesto del ranking en las ventas de la región al exterior, cayeron un 2,5\%, alcanzando los $130 \mathrm{M} €$. Las principales partidas son: vehículos automóviles (principalmente partes y accesorios de vehículos automóviles); maquinaria y aparatos mecánicos; legumbres, hortalizas sin conserva (ajos); materiales plásticos y sus manufacturas.

Desde el punto de vista importador, lo más reseñable en 2020 fue que, entre nuestros principales proveedores, destacan los crecimientos de Alemania (20,5\%), Bélgica $(6,5 \%)$ y Portugal $(2,9 \%)$.

Desde las instituciones se insiste en que, en un contexto tan globalizado como el actual, una excesiva concentración de los flujos comerciales puede suponer un mayor riesgo comercial o, cuando menos, una pérdida de oportunidades en otros mercados. Por eso, la Administración comercial española ha seleccionado los denominados PASE (Países con Actuación Sectorial Estratégica) con el objetivo de fomentar las exportaciones a mercados extracomunitarios.

\section{Análisis provincial de los flujos comerciales}

\subsection{Albacete}

El volumen de exportación de Albacete en 2020 se situó en $1.031 \mathrm{M} €$, lo cual ha supuesto una caída del 8,6\% respecto al año anterior.
Francia. Las exportaciones representaron el $22,8 \%$ del total exportado y han crecido un $7,3 \%$. Las principales partidas supusieron un $41 \%$ del total, y fueron: bebidas excepto zumos —principalmente vino a granel— (39 M€, 17\%); vidrio y sus manufacturas (29 M€, -11\%); y manufacturas de fundición, hierro y acero (28 M€, $32 \%$ ). El estudio histórico muestra una evolución positiva en los envíos al país vecino.

Italia. Las exportaciones representaron el $11,4 \%$ del total exportado. Las principales partidas supusieron un $58 \%$ del total, y fueron: vehículos, automóviles, tractores (33,4 M€, 35\%) -este año ocupa el primer puesto del ranking, desplazando a frutos secos (almendras) $(33,2$ M€, -19\%)-; y bebidas excepto zumos —en su mayoría vino a granel- (18 M€, -3,9\%). La tendencia muestra que las exportaciones a Italia llevan una tendencia alcista. Este año han aumentado un 3,1\% con respecto a 2019 .

Alemania. Las exportaciones representaron el $11,4 \%$ del total exportado. Las principales partidas supusieron un $46 \%$ del total, y fueron: aeronaves (20 M€, $-37 \%$ ); aluminio y sus manufacturas (17 M€, $-1,6 \%$ ); aparatos y material eléctrico ( $15 \mathrm{M} €$, 400\%). Este año las exportaciones han caído a niveles de 2014, por lo que habrá que esperar a 2021 para determinar si ha sido un hecho coyuntural o se ha iniciado una tendencia bajista.

Portugal. Las exportaciones representaron el $6,9 \%$ del total exportado. Las principales partidas supusieron un $38 \%$ del total, y fueron: bebidas excepto zumos - principalmente vino a granel- (14 M€, 16\%); máquinas y aparatos mecánicos (7,7 M€, 3\%); y vidrio y sus manufacturas (4,82 M€, - $25 \%)$. La tendencia muestra que las exportaciones a Portugal llevan una tendencia alcista iniciada en 2014. Este año han aumentado un $4,9 \%$ con respecto a 2019. 
Reino Unido. Las exportaciones representaron el 5,2\% del total exportado (53,6 M€). Las principales fueron: calzado; frutos secos; y máquinas y aparatos mecánicos, que ha desplazado a sectores como el queso.

En cuanto a la vertiente importadora de la provincia de Albacete, asciende a la cantidad de $823 \mathrm{M} €$, con un descenso respecto al pasado año del $2 \%$. La cuota de participación sobre la importación global de la región ha supuesto un $8,9 \%$ el último año, ocupando el tercer lugar, muy alejado de los dos primeros.

Francia. Las importaciones representaron el $23,9 \%$ del total importado. Las tres principales partidas supusieron un $66 \%$ del total, y fueron: leche y productos lácteos —principalmente quesos y mantequilla- (70 M€, 1,6\%); aeronaves (40 M€, -4,5\%); y legumbres y hortalizas - destacando en su mayoría las patatas - (20 M€, 10,4\%). La tendencia muestra que las importaciones a Francia van aumentando a un ritmo constante.

Alemania. Las importaciones representaron el $21,7 \%$ del total importado. Las principales partidas supusieron un $82 \%$ del total, y fueron: máquinas y aparatos mecánicos (121 M€, $10 \%$ ); aeronaves (16,6 M€, -3,7\%); y productos fotográficos o cinematográficos (8 M€, con una fuerte subida y colocándose en el tercer lugar del ranking). La tendencia muestra que las importaciones procedentes de Alemania van aumentando de forma constante, recuperándose tras la gran caída sufrida en el periodo 2012-2016.

China. Las importaciones fueron el 9,3\% del total, alcanzando los 76,6 M€. Las principales partidas constituyeron el $35 \%$ y fueron: máquinas y aparatos mecánicos (9,6 M€); aparatos y material eléctrico (9,4 M€); y muebles, sillas, lámparas — principalmente aparatos de alumbrado- (8,4 M€). Las importaciones a
China han evolucionado de manera estable desde 2015, pero este año las importaciones han caído un 17,2\%. Habrá que esperar a 2021 para determinar si ha sido un hecho coyuntural o estructural.

Portugal. Las importaciones representaron el $8,1 \%$ del total importado, alcanzando los $67 \mathrm{M}$. Las principales partidas supusieron un $66 \%$ del total, y fueron: otros productos quími$\cos (30 \mathrm{M} €)$; materias plásticas y sus manufacturas (8,2 M€); y manufacturas de fundición (6,3 M€). La tendencia muestra que las importaciones procedentes de Portugal presentan tendencias alcistas constantes. Este año las importaciones han crecido un $13,6 \%$ respecto a 2019.

Italia. Las importaciones representaron el $6,8 \%$ del total importado. Las tres principales partidas supusieron un $63 \%$ del total, y fueron: leche y productos lácteos —quesos- (13 M€, $21 \%$ ); máquinas y aparatos mecánicos (7 M€, $-31 \%$ ); y pieles (6 M€, -64\%). La evolución muestra que las importaciones procedentes de Italia presentan tendencias alcistas, pero que han caído bruscamente en 2020 (-29\%). Habrá que esperar a los datos de 2021 para determinar si ha sido un hecho coyuntural debido a la pandemia o si se han encontrado otros proveedores para los productos que se adquirían en este país.

\subsection{Ciudad Real}

Ciudad Real presenta un volumen de exportaciones, en 2020, de $1.980 \mathrm{M} €$, un 7,2\% menos que el año anterior. Su participación sobre el total de las exportaciones en Castilla-La Mancha se estabiliza en torno al $25 \%$, presentando este año un porcentaje de un 25,5. Ciudad Real ocupa por segundo año $\square$ 
consecutivo el segundo puesto del ranking regional en 2020.

Francia. Las exportaciones representaron el $12,9 \%$ del total exportado. Las principales partidas supusieron un $62 \%$ del total, y fueron: bebidas excepto zumos - principalmente vino a granel- (101 M€, -6\%); materias plásticas y sus manufacturas (33 M€, -21,6\%); y aparatos y material eléctrico (21 M€, 3,5\%). La tendencia muestra que las exportaciones a Francia siguen bajando. Este año han caído un 1,3\%, principalmente por el descenso de las dos primeras partidas.

Alemania: las exportaciones representaron el $11,3 \%$ del total exportado. Las tres principales partidas supusieron un $70 \%$ del total, y fueron: bebidas excepto zumos — destacando los envíos de vino a granel- (98 M€, 7,8\%); materias plásticas y sus manufacturas (39 M€, $-25 \%$ ); y máquinas y aparatos mecánicos (17 M€, 7,2\%). La tendencia muestra que las exportaciones a Alemania llevan una tendencia bajista iniciada en 2017. Este año la caída ha sido del $1,7 \%$ con respecto a 2019 , producida por el descenso en muchas partidas.

Italia. Las exportaciones representaron el $9,7 \%$ del total exportado. Las principales partidas supusieron un $66 \%$ del total, y fueron: grasa, aceite animal o vegetal -en su mayoría aceite de oliva virgen extra- (41 M€, -17,2\%); materias plásticas y sus manufacturas (39 M€, $-15 \%$ ); y bebidas excepto zumos —en su mayoría vino a granel y mosto- (36 M€, 6\%). Este año las exportaciones han alcanzado un nuevo mínimo superior al de 2016 por la caída de un $10,8 \%$ respecto a 2019 .

Estados Unidos. Las exportaciones supusieron el 9,5\% del total exportado, alcanzando los 174 M€ y situándose por primera vez dentro de los cinco primeros países destino de los productos ciudadrealeños. Las principales partidas representaron un $88 \%$ del total, y fueron: máquinas y aparatos mecánicos (83 M€, $93 \%$ ); aparatos y material eléctrico (36 M€, $16,6 \%$ ); y leche, productos lácteos —quesos en su totalidad- (33,78 M€, 23,7\%). Las exportaciones han alcanzado un nuevo máximo en la serie histórica tras aumentar un $36 \%$ los envíos respecto a 2019.

Portugal. Las exportaciones aglutinaron el $8,6 \%$ del total exportado. Las principales partidas representaron un $55 \%$ del total, y fueron: materias plásticas y sus manufacturas (47 M€, $-29 \%$ ); bebidas excepto zumos - vino en todos sus formatos y aguardientes- (28 M€, 9,8\%); y combustibles (12 M€, -14,7\%). La tendencia muestra que las exportaciones a Portugal llevaban una tendencia alcista, pero en 2020 han caído un $16,8 \%$, abandonando el cuarto puesto del ranking, por lo que habrá que esperar a los datos de 2021 para determinar si se ha revertido la tendencia.

Por lo que se refiere a la importación, Ciudad Real presentó un volumen de tan solo $634 \mathrm{M} €$ durante el ejercicio 2020 y una reducción de compras exteriores del $9,1 \%$ respecto al año anterior.

Francia se sitúa en 2020 como principal proveedor, adelantando a China, que ocupó este puesto durante 2018. Las importaciones representaron el $12,9 \%$ del total importado. Las principales partidas supusieron un $46 \%$ del total, y fueron: otros productos químicos (18 M€, $-124,7 \%$ ); máquinas y aparatos mecánicos (10 M€, 15,8\%); y aparatos y material eléctrico (9 M€, 30,6\%), partida que ha desplazado al cuarto puesto a perfumes. La tendencia muestra que en 2020 han caído las importaciones $(11,6 \%)$ a niveles inferiores de 2017. La caída se debe fundamentalmente a la pandemia y a la bajada de la compra de productos químicos y de vehículos, que ocupaba el tercer lugar $\square$ 
del ranking y ahora está en quinto lugar, con una caída del $54 \%$ respecto a 2020 .

China. Las importaciones representaron el $12,5 \%$ del total importado $(79,5 \mathrm{M} €)$. Las principales partidas supusieron un $61 \%$ del total, y fueron: aparatos y material eléctrico (27 M€, -35,2\%); vidrio y sus manufacturas (17 M€, 250\%); y manufacturas de piedra y yeso (5 M€, 134\%). Este año el total de las importaciones procedentes de China ha caído un 1,4\%. Este hecho se debe al desplome de la primera partida importada, que supone, ella sola, el $35 \%$ de las compras al país asiático. En general, si se observa la tendencia del periodo de estudio, se está amortiguando la caída de las compras tras el máximo alcanzado en 2017.

Italia. Las importaciones representaron el $11,8 \%$ del total importado, alcanzando los $75 \mathrm{M} €$. Las principales partidas supusieron un $40 \%$ del total, y fueron: aparatos y material eléctrico (10,5 M€, 150\%); otros productos químicos (10,4 M€, -24\%); y bebidas excepto zumos - destacando el vino a granel, el mosto y el alcohol- (9,1 M€, -6,2\%). Este año el total de las importaciones procedentes de Italia ha caído un 3,9\%, pero, en general, si se observa la tendencia del periodo de estudio, esta es alcista.

Portugal. Las importaciones representaron el $9,7 \%$ del total importado, alcanzando los $61,7 \mathrm{M} €$. Las principales partidas supusieron un $49 \%$ del total, y fueron: plomo y sus manufacturas (17 M€, 245\%); vidrio y sus manufacturas (6 M€); materias plásticas y sus manufacturas (5,5 M€). Este año las importaciones crecieron un $29 \%$ respecto al año anterior y Portugal se sitúa como cuarto proveedor de Ciudad Real. La tendencia de las compras a Portugal por parte de la provincia es claramente creciente.

Alemania. Las importaciones representaron el $8,8 \%$ del total importado, alcanzando los
55,8 M€. Las principales partidas supusieron un $43 \%$ del total, y fueron: materias plásticas y sus manufacturas (14,4 M€, 35\%); aparatos y material eléctrico ( $5 \mathrm{M} €, 33 \%$ ); y vehículos y automóviles (4,6 M€, -37\%). La tendencia muestra que, a pesar de la caída de las importaciones de Alemania en 2012, poco a poco las compras de Ciudad Real a este país se van recuperando, aumentando un 7,2\% en 2020.

\subsection{Cuenca}

La provincia de Cuenca presenta un volumen de exportaciones en 2020 de 602 M€, con un incremento del $13,6 \%$ respecto al año anterior y una cuota de participación del 8,4\% sobre el total de las exportaciones de Castilla-La Mancha.

Francia. Las exportaciones representaron el $24,7 \%$ del total exportado, alcanzando los 148,9 M€. Las principales partidas supusieron un $87 \%$ del total, y fueron: aparatos y material eléctrico (97 M€, 54,7\%); bebidas excepto zumos (20 M€, 1,2\%); y carne y despojos comestibles - principalmente carne de cerdo(12,3 M€, 7,6\%). La tendencia muestra que las exportaciones a Francia van aumentando año tras año, con un incremento del $33,8 \%$ en 2020.

China. Las exportaciones representaron el $16,7 \%$ del total exportado, alcanzando los 100,5 M€. Las principales partidas supusieron un $95 \%$ del total, y fueron: carne y despojos comestibles - principalmente carne de cerdo y sus despojos- (89 M€, 54\%); conservas de verdura o fruta - principalmente envíos de mosto- (3,6 M€, 35,2\%); y vehículos automóviles, tractores (3,1 M€, 200\%). Las exportaciones se han incrementado un $53,1 \%$ respecto a 2019, principalmente por el aumento de $\triangleright$ 
envíos de carne de porcino al país asiático. La tendencia general en el periodo de estudio es creciente.

Italia. Las exportaciones representaron el $6,9 \%$ del total exportado, alcanzando los 41,5 M€. Las principales partidas supusieron un $75 \%$ del total, y fueron: grasa, aceite animal o vegetal —en su mayoría aceite de oliva virgen extra- (12 M€, -48\%); hortalizas —en su mayoría ajos- (9,6 M€, 5,9\%); y carne y despojos comestibles (9 M€, -27\%). La tendencia muestra que las exportaciones a Italia presentan fluctuaciones. Este año las exportaciones han caído un $23 \%$ con respecto a 2019 por las fuertes caídas en las principales partidas.

Alemania. Las exportaciones representaron el $6,1 \%$ del total exportado, alcanzando los 36,8 M€. Las principales partidas supusieron un $79 \%$ del total, y fueron: ajos, vino y vino espumoso embotellado, y zumo de uva. La tendencia muestra que las exportaciones a Alemania llevan una orientación bajista iniciada en 2017, sin embargo, este año el aumento ha sido del $23,8 \%$ con respecto a 2019 , por el incremento de los envíos de la mayoría de las partidas.

Japón. Las exportaciones representaron el $6,1 \%$ del total exportado, alcanzando los 36,6 M€, y situando a Japón, por primera vez, dentro del ranking de los cinco primeros países compradores de productos conquenses. Las principales partidas supusieron un $93 \%$ del total, y fueron: carne de cerdo congelado; ajos; y vino embotellado. La tendencia de las exportaciones a Japón es claramente alcista.

El volumen de importación de la provincia de Cuenca en 2020 fue de 268 M€, con una subida del 34,2\% respecto a 2019.

El primer país proveedor de bienes de la provincia es Alemania. Las importaciones representaron el $20,7 \%$ del total importado. Las tres primeras partidas supusieron un $79 \%$ del total, y fueron: aparatos y material eléctrico (30 M€, 49\%); vehículos, automóviles y tractores $(6,8 \mathrm{M} €,-31 \%) ;$ y materias plásticas y sus manufacturas (6,4 M€, 92\%). Las importaciones en 2020 crecieron en un 2,5\% respecto al año anterior. La tendencia muestra una recuperación tras la caída de 2018.

China. Sus importaciones representaron el $14,3 \%$ del total importado alcanzando los $38,4 \mathrm{M} €$. Las tres primeras partidas supusieron un $51 \%$ del total, y fueron: aparatos y material eléctrico (13 M€, 180\%); piedra, metal precioso, joyería - principalmente bisutería- (3,6 $\mathrm{M}$, $-2,5 \%$ ); y otros productos de origen animal -principalmente tripas- (5,4 M€, 18\%). Este año las compras procedentes de China han crecido un $25,7 \%$ y la tendencia del periodo de estudio es claramente creciente.

Corea del Sur. Las importaciones de este país representaron el $14,2 \%$ del total, alcanzando los $38 \mathrm{M€}$. La primera partida supuso un $99 \%$ del total y fue la de otros productos químicos, en concreto reactivos de laboratorio. Este año las compras procedentes de Corea del Sur han crecido más de un $1.000 \%$ y habrá que esperar para determinar si ha sido una compra puntual o si Corea del Sur se convierte en uno de los principales proveedores de Cuenca.

Francia. Las importaciones representaron el $9,2 \%$ del total importado. Las tres primeras partidas supusieron un $70 \%$ del total, y fueron: conservas de verduras o fruta, zumos —en su mayoría zumo de pera- (9 M€, $11 \%$ ); aparatos y material eléctrico (4 M€, 25,3\%); y vehículos (3,7 M€, 92\%). Este año las importaciones de Francia han crecido un $7,9 \%$. Observando la tendencia desde 2011 vemos cómo las compras al país vecino van en aumento.

Italia: Las importaciones aglutinaron el 6,4\% del total, hasta alcanzar los 17,2 M€. Las tres $\triangleright$ 
primeras partidas supusieron un $78 \%$ del total, y fueron: máquinas y aparatos mecánicos (10,6 M€, 500\%); vehículos automóviles (1,41 M€, $-47 \%)$; y aparatos y material eléctrico (1,4 M€, $176 \%$ ). Las importaciones han aumentado en un $94,5 \%$ respecto al año anterior y la tendencia general del periodo de estudio es creciente.

\subsection{Guadalajara}

El volumen de exportación de la provincia de Guadalajara fue de 1.799 M€ en 2020, es decir, el $25 \%$ del total regional, ocupando este año el tercer lugar en el ranking regional. Las ventas de las empresas de Guadalajara han descendido un $11 \%$-más del doble que la media regional-, debido a la pandemia, que ha afectado a las marcas multinacionales que se ubican en la provincia.

Portugal. Las exportaciones aglutinaron el $45,1 \%$ del total exportado, alcanzando los 811 M€. Las principales partidas supusieron un $58 \%$ del total, y fueron: aparatos y material eléctrico (222 M€, 5,3\%); máquinas y aparatos mecánicos (172 M€, -3,6\%); y aluminio y sus manufacturas (76 $\mathrm{M} €, 1,3 \%$ ), que desbanca a prendas de vestir de punto (69 M€, -42,5\%). La tendencia del periodo de estudio muestra cómo las exportaciones a Portugal han experimentado un gran crecimiento, aunque este año han caído un $14,4 \%$.

Francia. Las exportaciones representaron el 9,6\% del total exportado, alcanzando los $172 \mathrm{M€}$. Las principales partidas supusieron un $51 \%$ del total, y fueron: aparatos y material eléctrico (52 M€, -0,5\%); papel cartón (18 M€, 49\%); y materias plásticas y sus manufacturas (17 M€, $-4,1 \%)$. La tendencia muestra que las exportaciones a Francia van aumentando año tras año de manera constante.
Alemania. Las exportaciones representaron el $5,8 \%$ del total exportado. Las principales partidas supusieron un $47 \%$ del total, y fueron: vehículos (21 M€, 73\%); manufacturas diversas metálicas (19,5 M€, -22\%); y prendas de vestir de punto (9,5 M€, 140\%). La tendencia muestra que las exportaciones a Alemania van aumentando año tras año de manera constante. En 2020 crecieron un 13,5\% respecto al año 2019.

Reino Unido. Las exportaciones representaron el $4,1 \%$ del total exportado (73 M€) y se colocan en el cuarto puesto del ranking, por delante de Italia. Las principales partidas supusieron un $49 \%$ del total, y fueron: muebles, sillas y lámparas (14 M€, -4,7\%); aparatos y material eléctrico (14 M€, 48\%); prendas de vestir de punto (11 M€, $28 \%$ ). En el conjunto de años del periodo de estudio, las exportaciones han presentado un gran crecimiento, en concreto un $6,4 \%$ en 2020.

Italia. Las exportaciones representaron el $3,6 \%$ del total exportado. Las principales partidas supusieron un $42 \%$ del total, y fueron: vidrio y sus manufacturas (10,5 M€, -20\%); vehículos automóviles y tractores (9 M€, -26\%); y aparatos y material eléctrico (14 M€, -40\%). Este año las exportaciones han caído un 20,7\% con respecto a 2019. La tendencia muestra que las exportaciones a Italia, en el conjunto de años, prácticamente permanecen estables.

En cuanto a la importación, el volumen en 2019 fue de $5.513 \mathrm{M} €$, un 0,7\% menos que el año anterior, superando ya la cifra récord de toda la serie alcanzada en 2007, que fue de 5.359 M€. El hecho de que el $60 \%$ de las importaciones regionales tengan como destino Guadalajara refleja que sigue siendo la provincia más dinámica, cuyo tejido industrial tiene gran peso en la región, impulsado por las compras de bienes de equipo principalmente. 
En cuanto a la importación en 2020 , el volumen fue de $5.115 \mathrm{M} €$, un $7,2 \%$ menos que el año anterior.

El primer puesto lo ocupa Alemania. Las importaciones representaron el $16,7 \%$ del total importado. Las tres primeras partidas suponen un $50 \%$ del total, y fueron: vehículos automóviles y tractores (190 M€, 20,4\%); máquinas y aparatos mecánicos (135 M€, 9,4\%); y productos farmacéuticos (100 M€, -37\%). Las importaciones procedentes del país germano han crecido en un $5 \%$ en el año 2019 , volviendo a la tendencia creciente de años anteriores.

Francia. Las importaciones representaron el $12,9 \%$ del total importado. Las tres primeras partidas supusieron un $50 \%$ del total, y fueron: vehículos automóviles y tractores (217 M€, -8,2\%); aparatos y material eléctrico (83 $\mathrm{M} €, 0,8 \%$ ); y otros productos químicos (35 M€, 60\%). Las importaciones procedentes del país galo han caído un $7,1 \%$ en el año 2020, por lo que habrá que esperar a los datos de 2021 para determinar la tendencia.

Países Bajos. Las importaciones representaron el $12,0 \%$ del total importado. Las tres primeras partidas supusieron un $70 \%$ del total, y fueron: productos farmacéuticos (217 M€, $27 \%$ ); aparatos y material eléctrico (124 M€, $-16 \%$ ); y bebidas excepto zumos - principalmente bebidas espirituosas- (90 M€, -42\%). Las importaciones procedentes de Países $\mathrm{Ba}$ jos han caído un 9,1\% en el año 2020. Habrá que esperar a los datos de 2021 para determinar si ha sido una caída coyuntural por la pandemia.

Irlanda. Las importaciones aglutinaron el $10,8 \%$ del total importado. Las tres primeras partidas representaron un $85 \%$ del total, y fueron: aparatos y material eléctrico (408 M€, -2,2\%); productos farmacéuticos (91 M€, -19\%); y máquinas y aparatos mecánicos (26 M€, -27\%).
Las importaciones procedentes de Irlanda han caído un 9,4\% en el año 2020 y, al igual que en los casos anteriores, habrá que esperar a los datos de 2021 para determinar la tendencia.

China. En 2020 las importaciones procedentes de este país asiático alcanzaron los $400 \mathrm{M} €$, el 7,8\% del total importado por Guadalajara. Las tres primeras partidas representaron un $41 \%$ del total, y fueron: aparatos y material eléctrico (179 $\mathrm{M€},-12 \%)$; máquinas y aparatos mecánicos (52 M€, -11\%); y prendas de vestir no de punto (26 M€, -37\%). Las importaciones procedentes de China han bajado un $10,5 \%$ en el año 2020.

\subsection{Toledo}

El volumen de exportaciones de Toledo en 2020 fue de $1.924 \mathrm{M} €$, un 2,6\% más que el año anterior. Ocupa la primera posición en el ranking exportador regional, con una cuota del $26,8 \%$, en el total de Castilla-La Mancha, casi dos puntos por delante de Ciudad Real y Guadalajara. Es, además, la provincia que ofrece una mayor diversificación sectorial en su exportación: los diez primeros sectores supusieron menos del $68 \%$ del total.

Portugal. Las exportaciones alcanzaron los $381,5 \mathrm{M} €$ y aglutinaron el $19,8 \%$ del total exportado. Las principales partidas supusieron un $50 \%$ del total, y fueron: productos farmacéuticos (76 M€, 0,2\%); caucho y sus manufacturas (71 M€, -6,2\%); y carne y despojos comestibles - principalmente carne de ganado bovino y porcino- (45 M€, 5\%). En 2020 las exportaciones a Portugal han caído un $4,7 \%$ respecto al año anterior, de modo que continúa la tendencia creciente de ventas desde la provincia de Toledo a nuestro país vecino. 
Francia. Las exportaciones representaron el $14,3 \%$ del total exportado, alcanzando los $276 \mathrm{M} €$. Las principales partidas supusieron un $33 \%$ del total, y fueron: aluminio y sus manufacturas (34 M€, $-23 \%$ ); bebidas excepto zumos - principalmente vino a granel- (33 M€, $2,8 \%$ ); y preparaciones alimenticias diversas (24 M€, 6,3\%). La tendencia muestra que las exportaciones a Francia están iniciando un cambio. La pendiente creciente se ha visto atenuada por los resultados del año anterior y de este año, que han supuesto una reducción de las exportaciones en un 6,3\%.

Alemania. Las exportaciones representaron el $11,2 \%$ del total exportado, hasta 214,8 M€. Las principales partidas supusieron un $47 \%$ del total, y fueron: carne y despojos comestibles (44 M€, 20,8\%); bebidas excepto zumos -principalmente el vino a granel- (35 M€, $10 \%$ ); y manufacturas de piedra y yeso (23 M€, $-59 \%$ ). La tendencia muestra que las exportaciones a Alemania van aumentando año tras año de manera constante, aunque en 2020 cayeron un $9,5 \%$ respecto a 2020 .

Italia. Las exportaciones representaron el $6,3 \%$ del total exportado. Las principales partidas supusieron un $48 \%$ del total, y fueron: grasa y aceites —destacando el aceite de oliva virgen extra- (31 M€, -25\%); prendas de vestir de punto (13,8 M€, $-37 \%)$; aceites esenciales y perfumes (13 M€, $-21 \%$ ). La tendencia muestra que las exportaciones a Italia, que en los años de estudio era creciente, se está viendo atenuada. Este año las ventas cayeron un $18 \%$.

Bélgica, que por primera vez se sitúa dentro de los cinco primeros, alcanzó los $106 \mathrm{M}$, aglutinando el 5,5\% del total exportado. Las principales partidas representaron un $71 \%$ del total, y fueron: aparatos ópticos, de medida, médicos -principalmente jeringas y agujas- (50 M€, envío puntual en este año); sal, yeso, piedras sin trabajar (22 M€, envío puntual); y productos de cereales y pastelería (4,5 M€, 200\%). Este año las exportaciones crecieron un $240 \%$, por los dos envíos de las dos principales partidas, por lo que habrá que esperar a los siguientes años para confirmar si se consolidan los clientes y Bélgica mantiene su posición en el ranking.

Las importaciones en la provincia de Toledo durante 2020 alcanzaron los 2.441 M€. Las importaciones toledanas supusieron en 2020 un $26 \%$ del total de la región. Toledo es la segunda provincia más importadora después de Guadalajara y ambas son las que marcan prácticamente la totalidad de las importaciones regionales, con el $81,3 \%$ del total de CLM.

El primer puesto del ranking lo ocupa Alemania, cuyas importaciones representaron el $21,7 \%$ del total importado, alcanzando $529 \mathrm{M€}$. Las tres primeras partidas supusieron un $63 \%$ del total, y fueron: máquinas y aparatos mecánicos (177 M€, 600\%); productos farmacéuti$\cos (127 \mathrm{M} €, 58 \%)$; manufacturas de piedra y yeso (32 M€, 180\%). Las importaciones procedentes del país germano han aumentado en un $82,1 \%$ en el año 2020 , y continúa la tendencia creciente de las compras a este país iniciada en años anteriores.

China. Las importaciones representaron el $13,1 \%$ del total importado, alcanzando $318 \mathrm{M} €$. Las tres primeras partidas supusieron un $43 \%$ del total, y fueron: máquinas y aparatos mecáni$\cos$ (70 M€, 74\%); aparatos y material eléctrico (44 M€, 18\%); y muebles, sillas y lámparas (25 M€, $-15 \%$ ). Las importaciones procedentes del país asiático han aumentado en un $23,8 \%$. La tendencia general del periodo de estudio muestra una recuperación y registra un nuevo máximo.

Italia. Las importaciones representaron el $10,4 \%$ del total importado (253 M€). Las tres primeras partidas supusieron un $53 \%$ del $\triangleright$ 
total importado, y fueron: productos farmacéuticos (84 M€, 45\%); caucho y sus manufacturas (30,4 M€, 29,2\%); y máquinas y aparatos mecánicos (22,7 M€, -8,2\%). Las importaciones procedentes de Italia se han contraído en este último año en un 9,4\%. La tendencia del periodo de estudio muestra que las importaciones procedentes de Italia presentan bastante volatilidad, los máximos se alcanzaron en 2012 y 2017, y parece que en 2020 se inicia otro periodo de crecimiento tras el mínimo de 2019.

Francia. Las importaciones representaron el $9,7 \%$ del total importado (237 M€) y las tres primeras partidas, un $27 \%$ del total, y fueron: caucho y sus manufacturas (30 M€, -29,7\%); preparaciones alimenticias (21 M€, 4,5\%); y productos de cereales, de pastelería (15 M€, $-12,5 \%$ ). Las importaciones procedentes del país galo han disminuido en un $16,6 \%$.

Portugal. Las importaciones aglutinaron el $7,4 \%$ del total importado (180 M€). Las tres primeras partidas supusieron un $33 \%$ del total, y fueron: leche, productos lácteos - principalmente yogures y productos lácteos- (24 M€, $9,6 \%)$; grasas, aceite animal o vegetal -margarina y aceite de oliva virgen extra- (19 M€, $500 \%$ ); y materias plásticas y sus manufacturas (17 M€, 22,8\%). Las importaciones procedentes de Portugal han aumentado un 16,3\% respecto al año anterior. La tendencia muestra crecimientos prácticamente constantes en el periodo de estudio.

\section{Perspectivas a corto plazo del comercio exterior de Castilla-La Mancha en 2021. Modelo de previsión}

Los datos obtenidos en el primer trimestre de 2020 acerca de los flujos comerciales de la región nos dan una primera aproximación a las $\triangleright$

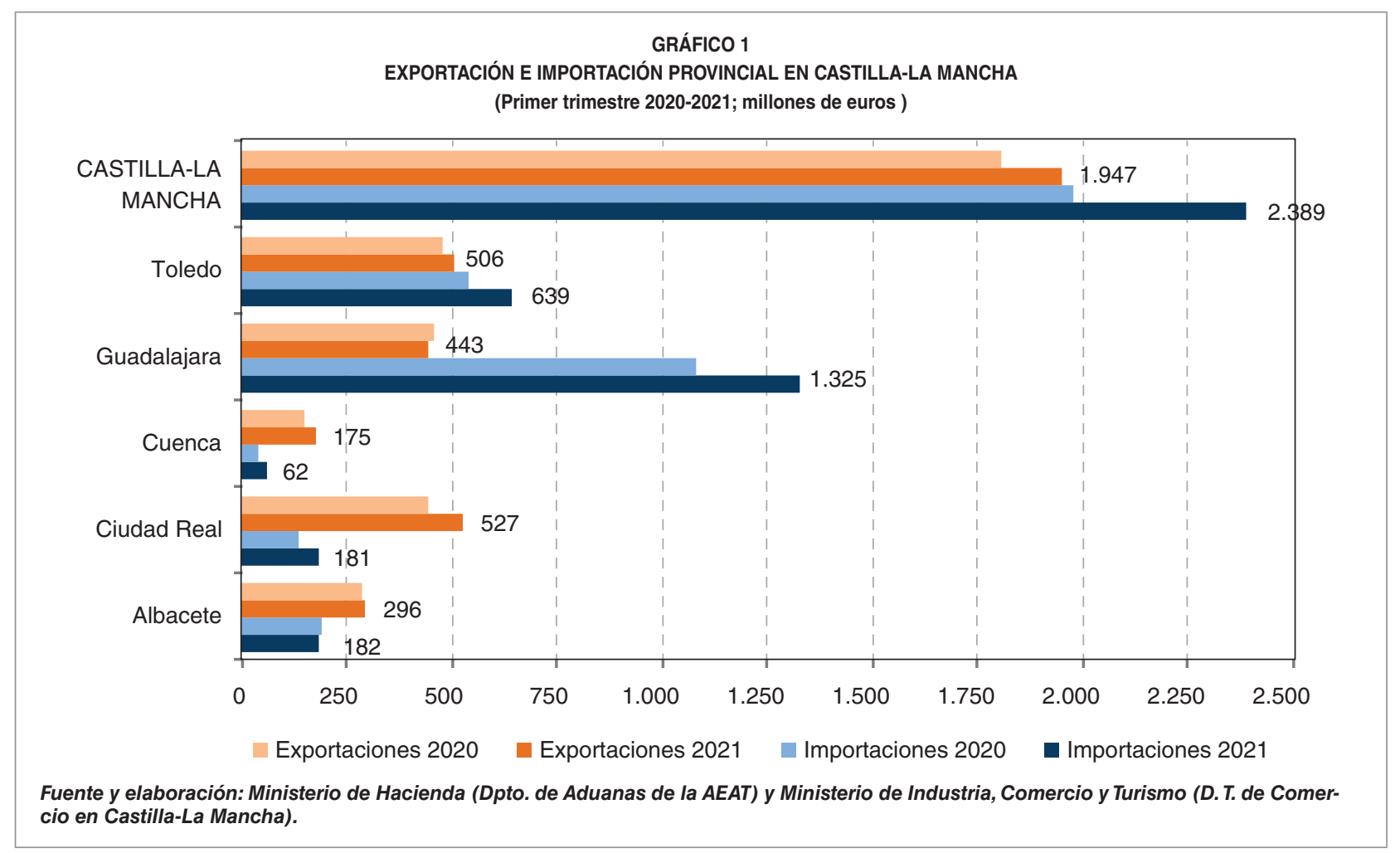


cifras que obtendremos para finales de año a través del modelo de previsión.

\subsection{Análisis sectorial}

A nivel agregado, los veinte capítulos más importantes de la exportación regional representan más del $78,9 \%$ del total de nuestras exportaciones, y se ha producido, en estos primeros meses del año, un crecimiento del 7,6\% respecto al mismo periodo de 2020. Por lo que se mantiene la tendencia positiva advertida en los últimos años y supera las tendencias que experimentan dichos sectores a nivel nacional. Por otra parte, no se aprecia un cambio importante en el ranking de los sectores más exportadores, si acaso ligeras variaciones en el orden de los mismos.

\subsection{Principales mercados exteriores}

Durante los primeros tres meses del año, la exportación de Castilla-La Mancha está muy concentrada en Europa, que absorbe el 77,3\% de nuestras ventas al exterior, seguida de lejos por Asia (11,0\%), América (7,1\%), África $(4,1 \%)$ y Oceanía $(0,5 \%)$. Por regiones, se observa un incremento importante $(21,5 \%)$ de los envíos de productos castellanomanchegos a Asia, empujados, como se verá posteriormente, por China, a Europa $(11,6 \%)$ y a Oceanía $(36,7 \%)$, y un descenso notable de las exportaciones a América (-28,3\%) y a África (-5,8\%).

Haciendo un estudio por países, los diez principales destinos acaparan el $72,2 \%$ del total, marcando claramente la tendencia del total de nuestras ventas al exterior.

Portugal (360 M€), Francia (333 M€), Italia (173 M€), Alemania (164 M€) y China (79 M€) vienen siendo, por ese orden, los principales destinos de la exportación castellanomanchega. No obstante, se observa una debilitación fuerte de la demanda por parte de Alemania $(-13,5 \%)$, una subida moderada por parte de Portugal $(2,2 \%)$ y un fuerte incremento de las exportaciones a China $(76,5 \%)$, Francia $(29,7 \%)$ e Italia $(22,5 \%)$.

Los cinco siguientes países que siguen en el ranking son: Reino Unido (70 M€), Estados Unidos (70 M€), Bélgica (65 M€), Polonia (49 M€) y Turquía (42 M€). Bélgica y Polonia han incrementado notablemente sus compras, mientras que en Reino Unido, Estados Unidos y Turquía han caído un $-12,7 \%$, un $-37,6 \%$ y un $-8,9 \%$, respectivamente.

En general, 2021 ha empezado con buen ritmo y algunos países como Finlandia (457\%), Dinamarca (168\%), Austria (100\%), Suecia ( $91 \%)$, China (76\%), Bélgica (55\%) o Polonia $(36 \%)$ han tenido un arranque prometedor.

\subsection{Modelo de previsión}

El comportamiento del modelo de previsión en los años anteriores ha sido bastante satisfactorio, tal y como se podrá comprobar en las cifras de previsión obtenidas. No obstante, situaciones excepcionales y, en cierta medida inesperadas, tanto en el ámbito económico como político tienen su influencia en la capacidad predictiva y alteran la senda natural de evolución, tanto de las exportaciones como de la capacidad de importación. En cualquier caso, constatar la tendencia enormemente positiva de Castilla-La Mancha respecto a otras comunidades autónomas y respecto a España, en todos estos años.

La actividad exportadora de nuestra comunidad autónoma en 2021 , debido a la crisis $\triangleright$ 


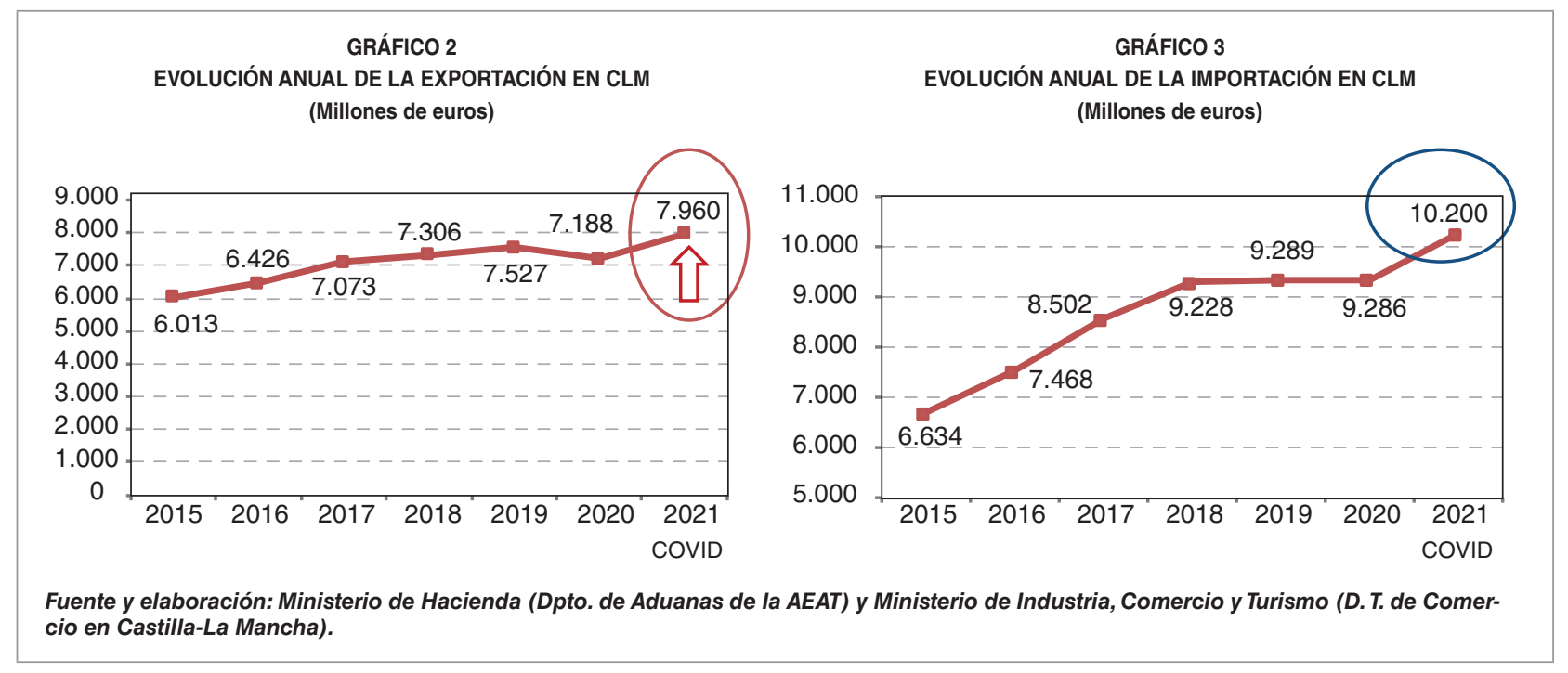

de la COVID-19, se verá influenciada por la evolución de la pandemia y el efecto de las medidas sanitarias. Sin duda, ayudarán los programas internacionales de cooperación, la evolución de los mercados, la necesidad del fomento del comercio exterior para mejorar el PIB y la transformación digital. Y todo ello pese a la creciente ola de neoproteccionismo en contraposición del multilateralismo, la tendencia al autoabastecimiento y la posible reactivación de conflictos internos en las diferentes naciones.

La cifra de exportaciones de CLM podría situarse en los $7.960 \mathrm{M} €$ a finales de 2021, lo que supondría un aumento del $10,7 \%$ respecto a 2020. Por otro lado, se prevé que para el conjunto de España las exportaciones se sitúen en los 287.000 M€ en 2021, con un ascenso del $10,2 \%$ respecto a 2020 .

Así mismo, la importación regional en 2021 aumentaría a los 10.200 M€, que supondrían un aumento del $9,8 \%$, lo que haría crecer el déficit comercial regional, situándolo en 2.240 M€. Igualmente, a nivel nacional, el aumento esperado de las importaciones las situaría en unos $284.000 \mathrm{M} €(3,7 \%)$.

\section{Perfil de la empresa exportadora de Castilla-La Mancha en 2020 y perspectivas para 2021}

Un elemento importante para analizar los flujos comerciales es conocer las empresas que están dispuestas a expandir su negocio fuera de nuestras fronteras, con objeto de conseguir una consolidación en los mercados exteriores. Esta consolidación no siempre es fácil y rápida, dado que ello conlleva unos costes que no todas las empresas están en disposición de afrontar en sus primeros pasos, y el proceso puede resultar dilatado en el tiempo.

La principal característica del tejido exportador en Castilla-La Mancha es la dualidad de las empresas exportadoras, con la coexistencia de un elevado número de empresas que exportan poco y de forma regular, y un número reducido de empresas que concentran el grueso de la exportación en la región.

El análisis del número de empresas que operan en el comercio internacional se topa con la obligación de registrarse ante Aduanas, lo cual depende del valor exportado en función del mercado de destino. Para obviar en $\triangleright$ 


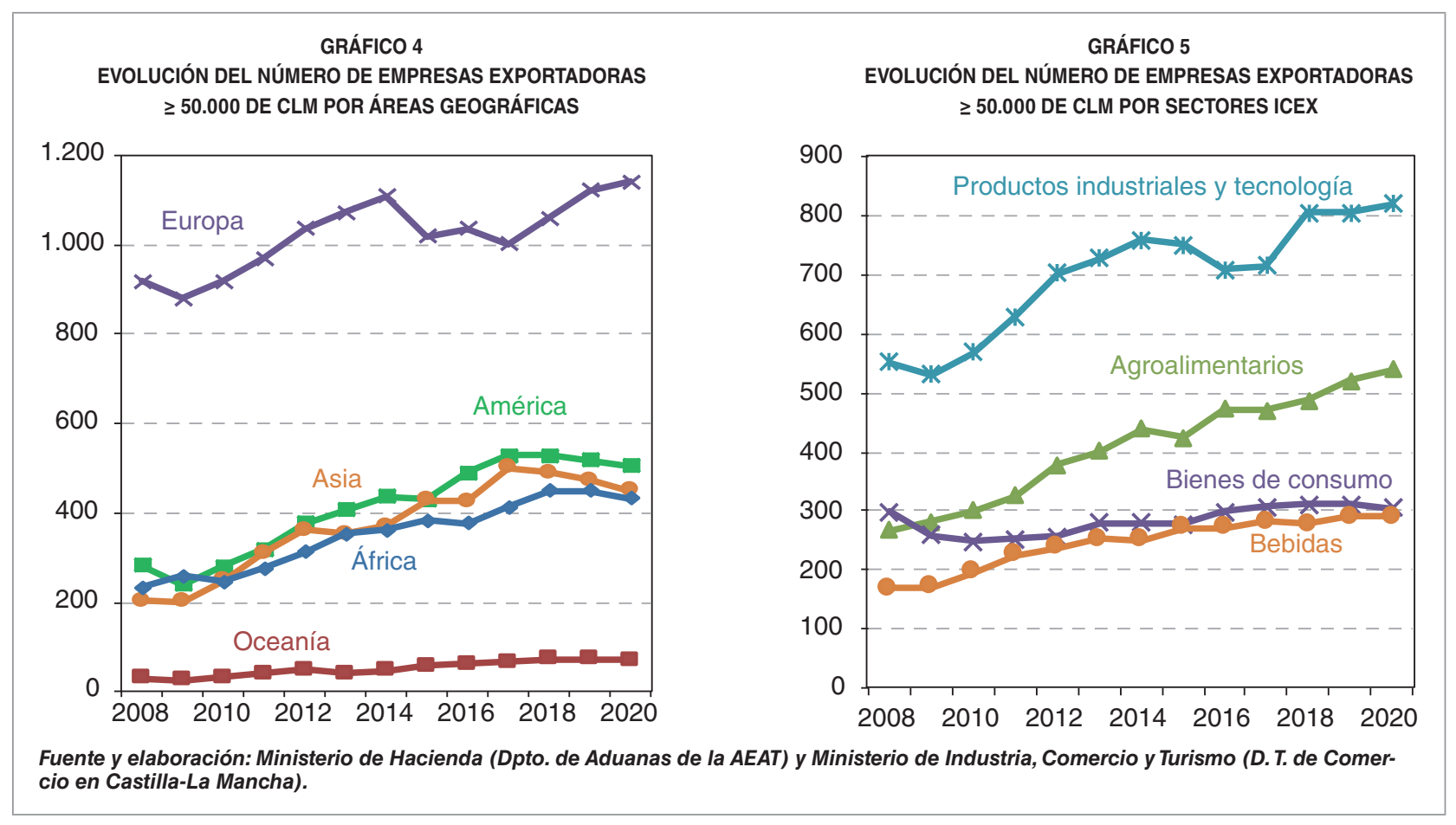

parte este problema, vamos a filtrar el número de operadores, elevando la cifra mínima a los 50.000 euros, lo que supone no incluir en el estudio operadores a terceros países con exportaciones de escasa cuantía, nivelándolo en parte a la obligación de registrarse cuando se realiza una expedición a mercados de la UE.

Así, tras esa selección de empresas que exportaron, al menos, 50.000 euros al año en 2020, nos aparecen 1.791 empresas que agrupan nada menos que el 99,6\% del total exportado en CLM, mientras que estas representan apenas el $29,4 \%$ del total de operadores (porcentaje ligeramente superior a 2019, con un $25,8 \%$ ). Además, se comprueba la existencia de una correlación positiva entre exportación regular y tamaño de la empresa, de ahí que numerosos estudios destaquen la conveniencia de fomentar el aumento del tamaño de las empresas como una vía para aumentar su competitividad y su grado de internacionalización.

Los destinos preferidos de nuestras empresas son, por tanto, países cercanos a nuestro entorno: Portugal, Francia, Alemania e Italia. No obstante, destacamos también el número de empresas que dirigen sus productos a Reino Unido, Estados Unidos e incluso China.

\section{Conclusiones}

Debido a la crisis de la COVID-19, el volumen de exportaciones de Castilla-La Mancha en 2020 se situó en 7.188,1 M€, un 4,5\% menos que en 2019, aunque la caída fue más suave que la media nacional, que se situó en el -10\%. La participación de Castilla-La Mancha sobre el total exportado a nivel nacional se mantiene en el 2,8\%. Por su parte, el volumen total de importaciones en 2020 se mantuvo estable en los 9.285,7 M€. En cuanto al saldo comercial, los datos de CLM durante 2020 muestran un aumento del déficit comercial del 19,1\% (de los 1.761,2 M€ a los 2.097,5 M€). A nivel nacional, el saldo fue $\square$ 
también negativo, disminuyendo un 58,0\% respecto al año anterior, alcanzando la cifra de los -13.422 M€.

Nuestro modelo de previsión indica que en Castilla-La Mancha las exportaciones en 2021 podrían situarse en los $7.960 \mathrm{M} €$, aumentando un $10,7 \%$, mientras que la importación regional también aumentaría hasta los 10.200 M€ $(9,8 \%)$, empeorando el déficit comercial regional y situándolo en -2.240 M€. 
